Arabic sciences and philosophy, 31 (2021): 95-126

doi:10.1017/S0957423920000090

C) The Author(s), 2021. Published by Cambridge University Press. This is an Open Access article, distributed under the terms of the Creative Commons Attribution licence (http://creativecommons.org/licenses/by/4.0/), which permits unrestricted re-use, distribution, and reproduction in any medium, provided the original work is properly cited.

\title{
AVICENNA ON GRASPING MATHEMATICAL CONCEPTS
}

\author{
MOHAMMAD SALEH ZAREPOUR \\ Department of Philosophy \\ University of Birmingham \\ Email:m.s.zarepour@bham.ac.uk
}

\begin{abstract}
According to Avicenna, some of the objects of mathematics exist and some do not. Every existing mathematical object is a non-sensible connotational attribute of a physical object and can be perceived by the faculty of estimation. Non-existing mathematical objects can be represented and perceived by the faculty of imagination through separating and combining parts of the images of existing mathematical objects that are previously perceived by estimation. In any case, even non-existing mathematical objects should be considered as properties of material entities. They can never be grasped as fully immaterial entities. Avicenna believes that we cannot grasp any mathematical concepts unless we first have some specific perceptual experiences. It is only through the ineliminable and irreplaceable operation of the faculties of estimation and imagination upon some sensible data that we can grasp mathematical concepts. This shows that Avicenna endorses some sort of concept empiricism about mathematics.
\end{abstract}

Résumé. Selon Avicenne, certains objets des mathématiques existent et d'autres non. Chaque objet mathématique existant est un attribut connotationnel non sensible d'un objet physique et peut être perçu par la faculté d'estimation. Les objets mathématiques non existants peuvent être représentés et perçus par la faculté d'imagination en séparant et en combinant des parties d'images d'objets mathématiques existants qui sont précédemment perçues par estimation. Dans tous les cas, même les objets mathématiques non existants doivent être considérés comme des propriétés d'entités matérielles. Ils ne peuvent jamais être saisis comme des entités totalement immatérielles. Avicenne pense que nous ne pouvons saisir aucun concept mathématique à moins d'avoir au préalable des expériences perceptives spécifiques. Ce n'est que par l'opération non éliminable et irremplaçable des facultés d'estimation et d'imagination sur certaines données sensibles que nous pouvons saisir les concepts mathématiques. Cela montre qu'Avicenne approuve une sorte d'empirisme conceptuel sur les mathématiques.

\section{INTRODUCTION}

The philosophy of mathematics, in general, aims to answer two fundamental questions. The ontological question concerns the nature of 
the things studied by mathematics. The ontology of mathematics investigates the metaphysical status of mathematical objects (e. g., numbers and geometrical shapes). The epistemological question, on the other hand, is about how we can grasp mathematical knowledge. The epistemology of mathematics explores how - by which cognitive faculties, for example - we can know mathematical objects, their properties, and their relations. It examines the role of sense perception in the formation of our mathematical knowledge and determines the extent to which our knowledge of mathematics is a priori, certain, or necessary. In this paper, I discuss part of Avicenna's answer to the epistemological question about mathematics ${ }^{1}$.

Compared to Avicenna's general theory of knowledge and his epistemology of what we call today experimental sciences (e.g., medicine), which have been widely discussed in modern scholarship, his epistemology of mathematics has been neglected except by a few scholars ${ }^{2}$. This negligence is surely not due to the absence of discussion of mathematical knowledge in Avicenna's oeuvre. Quite the contrary, his epistemological

${ }^{1}$ What I refer to by "mathematics" is restricted to pure mathematics (i. e., arithmetic and geometry) and does not include any applied mathematical sciences (e. g., astronomy and music).

${ }^{2}$ For studies on Avicenna's general epistemology see, among others, Sari Nuseibeh, "Al-caql al-qudsi: Avicenna's subjective theory of knowledge," Studia Islamica, vol. 69 (1989), p. 39-54; Jon McGinnis, "Avicenna's naturalized epistemology and scientific method," in Shahid Rahman, Tony Street, and Hassan Tahiri (eds.), The unity of science in the Arabic tradition (Dordrecht, 2008), p. 129-52; Dimitri Gutas, "The empiricism of Avicenna," Oriens, vol. 40, no. 2 (2012), p. 391-436; Deborah L. Black, "Certitude, justification, and the principles of knowledge in Avicenna's epistemology," in Peter Adamson (ed.), Interpreting Avicenna: Critical essays (Cambridge, 2013), p. 120-42; and Ricardo Strobino, "Principles of scientific knowledge and the psychology of (their) intellection in Avicenna's Kitāb al-burhān," in Joël Biard (ed.), Raison et démonstration: Les commentaires médiévaux sur les Seconds analytiques (Turnhout, 2015), p. 31-45. For studies on his epistemology of experimental sciences, and of medical sciences in particular, see Sari Nuseibeh, "Avicenna: Medicine and scepticism," Koroth, vol. 8, no. 1-2 (1981), p. 9-20; Dimitri Gutas, "Medical theory and scientific method in the age of Avicenna," in David C. Reisman and Ahmed H. AlRahim (eds.), Before and after Avicenna: Proceedings of the first conference of the Avicenna Study Group (Leiden, 2003), p. 145-62; and Peter E. Pormann, "Avicenna on medical practice, epistemology, and the physiology of the inner senses," in Peter Adamson (ed.), Interpreting Avicenna: Critical essays (Cambridge, 2013), p. 91-108. Two exceptions to the wide negligence of Avicenna's epistemology of mathematics in the secondary literature are provided by Dimitri Gutas, "Intuition and thinking: The evolving structure of Avicenna's epistemology," in Robert Wisnovsky (ed.), Aspects of Avicenna (Princeton, 2001), p. 1-38, and Mohammad Ardeshir, "Ibn Sīnā's philosophy of mathematics," in Shahid Rahman, Tony Street, and Hassan Tahiri (eds.), The unity of science in the Arabic tradition (Dordrecht: 2008), p. 43-62. 
discussions include numerous allusions to how we obtain mathematical knowledge. For instance, his descriptions of the functions of our cognitive faculties, his analysis of the foundational propositions of theoretical sciences, and his development of a general theory of demonstration are accompanied by many illustrative mathematical examples which clarify the mechanisms through which mathematical knowledge can be attained. A careful analysis of these references to mathematics can reveal the core elements of an ingenious epistemology of mathematics to which Avicenna is committed. This study is an attempt to provide such an analysis.

All instances of knowledge for Avicenna are either concepts or propositions. Notoriously, Avicenna believes that acquiring knowledge is either conceiving a concept (tasawwur) or assenting to the truth of a propo$\operatorname{sition}^{3}(\operatorname{tas} d \bar{\imath} q)$. Given this general understanding of knowledge, we can conclude that for Avicenna acquiring mathematical knowledge is either forming mathematical concepts (e.g., the concept "four" or the concept "triangle") or assenting to the truth of mathematical theorems (e. g., the theorem that four is even or the theorem that the sum of the three interior angles of the triangle equals two right angles). Accordingly, the question of how we grasp mathematical knowledge can be reduced to two more specific questions: (1) how do we grasp mathematical concepts?, and (2) how do we make mathematical judgments and assent to the truth of mathematical propositions ${ }^{4}$ ? Not surprisingly, the answer to the latter

3 These two notions are discussed in various places in the Avicennan corpus. See, among others, his treatment in the "Demonstration" part of The healing (Al-šif $\bar{a}$, Al-mantiqu, Al-burhān, ed. Abū l-cAlāo cAfîfĩ (Cairo, 1956), chap. I.1, p. 51-53), the "Salvation" (Al-nağāt, ed. Mohammad Taqī Danešpažūh (Tehran, 1985), p. 7, 112-

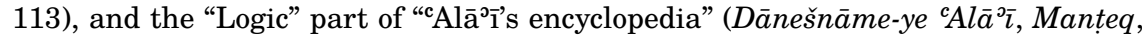
ed. Mohammad Mocīn (Hamadan, 2004), p. 5-6). Sabra has discussed Avicenna's understanding of these notions and clarified their connections to some similar notions in Aristotle. See Abdelhamid I. Sabra, "Avicenna on the subject matter of logic," The journal of philosophy vol. 77, no. 11 (1980), p. 746-64. As pointed out by Strobino ("Principles of scientific knowledge," 33) using the terminology of tasawwur and tașdī $q$ has become "mainstream in the Arabic tradition after al-Fārābī." For a discussion of these concepts in Avicenna and al-Fārābī, see Deborah L. Black, Logic and Aristotle's rhetoric and poetics in medieval Arabic philosophy (Leiden, 1990), p. 7178. The history of these concepts (and their counterparts) in different philosophical traditions has been reviewed in Harry Austryn Wolfson, "The terms tașawwur and tașdī $q$ in Arabic philosophy and their Greek, Latin and Hebrew equivalents," The Muslim world, vol. 33, no. 2 (1943), p. 114-28.

${ }^{4}$ Indeed, the general question of knowledge acquisition can be reduced to the more specific questions of how we can make tasawwur and tasdīq. Perhaps that is why Black (Logic and Aristotle's rhetoric, p. 71) believes that these notions "can be viewed as the cornerstones of medieval Arabic epistemology." 
question depends partly on the answer to the former. We cannot know a proposition unless we know the concepts from which the proposition is constituted. Knowing the conceptual components of a proposition is a necessary - though not sufficient - condition for knowing that proposition. For instance, without first acquiring the concepts "four" and "even", no one can know that every four is even. So (1) should be addressed before (2). In this paper, I investigate Avicenna's answer to (1).

Avicenna's answer to these two questions hinges heavily on his ontology of mathematics, on the one hand, and his general psychology, on the other. The mechanisms through which we grasp (either conceptual or propositional) knowledge of an object and the cognitive faculties we employ for this purpose depend, at least partly, on the nature of the object. For instance, it seems quite plausible to think that our knowledge of fully separate ( $m u f \bar{r} r a q$ ) entities cannot be grasped through the same mechanisms by which we perceive sensible (maḥsūs) things. It seems reasonable to consider these two groups of entities as the objects of different cognitive faculties. It means that to arrive at a comprehensive understanding of Avicenna's epistemology of mathematics, we need a background knowledge of his views on the nature of mathematical objects and on human psychology. Therefore, in the following section, I discuss these preliminary issues.

In section three, I investigate the roles Avicenna attributes to different cognitive faculties in the process of the formation of mathematical concepts. The faculty of estimation (wahm), as will be illustrated, is the protagonist of his scenario on the epistemology of mathematical concepts. The primary function of this faculty, however, hinges on what is perceived through the external senses. A careful consideration of a thought experiment proposed by Avicenna shows that the formation of mathematical concepts cannot be independent from the perception of sensible objects of the extramental world, or so Avicenna argues. He therefore seems to endorse some sort of concept empiricism about mathematics, albeit in a very specific sense which will be delineated. Mathematical concepts are formed through a process of abstraction (tajri $\bar{d}$ ) which begins from experiencing some physical objects and proceeds under the heavy influence of estimation. I also discuss, in the same section, how the faculty of imagination enables us to form and grasp conceptions of mathematical objects that have no correlate in the sensible world.

In section four, I turn to a more specific problem about the formation of mathematical concepts. Mathematical objects (e.g., circles), as we conceptualize them, are perfect and exact in a way that physical ob- 
jects (e.g., circular material things) at least apparently cannot be. For instance, there seems to be no perfectly circular plane in the material world such that all points on its boundary (i.e., its circumference) are at exactly the same distance from a fixed point (i. e., its center). Sensible objects of the extramental world are at best imperfect approximations of ideal mathematical objects that we conceptualize in the mind. So one might wonder how, according to Avicenna, we can proceed from the perception of imperfect physical objects to the formation of perfect mathematical concepts. The first explanation which might come to mind is that for Avicenna abstraction is a machinery for constructing perfect mathematical entities which cannot exist in the extramental world. I will argue, however, that this suggestion is untenable, and that there is convincing evidence that Avicenna accepts that perfect mathematical objects can in principle exist in the physical world. These entities, like many other objects of estimation, might not be sensible but can actually exist in the extramental realm and be perceived by this multifunctional cognitive faculty. I close in section five by providing some concluding remarks.

\section{PRELIMINARIES}

What are the objects that mathematical theorems are about (or true of)? What is the nature of mathematical objects for Avicenna ${ }^{5}$ ? Roughly speaking, Avicenna believes that mathematical objects are not ideal Platonic forms. He denies that mathematical objects are fully separate from matter both in the mind and in the extramental world ${ }^{6}$. Moreover, he

${ }^{5}$ I have elsewhere presented the subtleties of his theory of mathematical objects. See Mohammad Saleh Zarepour, "Avicenna on the nature of mathematical objects," Dialogue, vol. 55, no. 3 (2016), p. 511-36. My interpretation of his view differs substantially from the alternatives proposed in the following works: Ardeshir, "Ibn Sīnā's philosophy of mathematics;" Jon McGinnis, "A penetrating question in the history of ideas: Space, dimensionality and interpenetration in the thought of Avicenna," Arabic sciences and philosophy, vol. 16, no. 1 (2006), p. 47-69, and "Experimental thoughts on thought experiments in medieval Islam," in Michael T. Stuart, Yiftach Fehige, and James Robert Brown (eds.), The Routledge companion to thought experiments (London, 2017), p. 77-91; and Hassan Tahiri, Mathematics and the mind: An introduction into Ibn Sinnā's theory of knowledge (Dordrecht, 2016).

6 The core elements of Avicenna's arguments against mathematical Platonism are expounded elsewhere. See Michael E. Marmura, "Avicenna's critique of Platonists in book VII, chapter 2 of the Metaphysics of his Healing," in J. Montgomery (ed.), Arabic theology, Arabic philosophy: From the many to the one. Essays in celebration of Richard M. Frank (Louvain, 2006), p. 355-69, and M. S. Zarepour, "Avicenna against mathematical Platonism," Oriens, vol. 47, no. 3-4 (2019), p. 197-243. 
does not believe that mathematical objects are perfect mental constructions that have no counterpart in the imperfect extramental reality ${ }^{7}$. Mathematical objects for Avicenna are specific properties of physical objects ${ }^{8}$. They can, and many of them do, actually exist in the extramental realm. However, they are not independent immaterial entities and their existence depends on the existence of the physical objects of which they are properties. Since every object of the physical world is constituted of a certain kind of matter (e. g., wood and gold), mathematical objects, in the extramental reality, are necessarily associated with particular kinds of matter. Stated another way, since there is no material object that is not of a determinate kind of matter, every mathematical entity - being a specific property of a material object - is attached to some particular kind of matter. Therefore, there can be no triangle, for example, in the physical world that is neither wooden, nor golden, nor of any other particular species of matter. Triangles do, or at least can, exist in the extramental world but only in association with some determinate kinds of matter, or so Avicenna claims. In the mind, mathematical objects can in principle be stripped of all special kinds of matter they are attached to in the physical world. Nonetheless, inasmuch as they are subject to mathematical studies, even in the mind they should be considered as properties following upon matter. So, in the mind, they are still associated with materiality, even though not with any specific kind of matter. Avicenna explicitly mentions that if we do not consider number as a specific property of material things (i. e., if we consider it as an entity fully separate from matter), then it would not be receptive to any increase or decrease, and, consequently, it cannot be subject to mathematical studies. It must in that case be studied by metaphysics ${ }^{9}$. Similarly, he argues that although we can detach geometrical shapes from all specific kinds of matter accompanying them in the physical world, they cannot be fully separate from materiality in general. Even in the mind they cannot be perceived except as material entities ${ }^{10}$. In sum, according to Avicenna,

${ }^{7}$ Ardeshir, McGinnis, and Tahiri (in the works mentioned in note 5) argue that mathematical objects for Avicenna are, in one way or another, mental objects. However, they offer different recipes for the construction of such objects.

${ }^{8}$ Numbers $\left({ }^{0} a^{c} d \bar{a} d\right)$ are the objects of arithmetic, and magnitudes (maquadirr) are (the most general representatives of) the objects of geometry. Avicenna argues, in The Metaphysics of the Healing, ed. and trans. Michael E. Marmura (Provo, 2005), chap. III.3-4, that both numbers and magnitudes are accident $\left({ }^{c}\right.$ arad $)$.

${ }^{9}$ Avicenna, The Metaphysics of the Healing, chap. I.3, p. 18-19.

${ }^{10}$ Moreover, Avicenna (The Metaphysics of the Healing, chap. VII.2, p. 249) makes the even stronger claim that "the definitions of geometrical [figures] among mathemat- 
mathematicians consider the object of their studies as entities that are separated from all determinate kinds of matter but still attached to materiality itself ${ }^{11}$. In this respect, mathematical objects lie between (1) the category of the objects that are fully separate from matter and materiality either in the mind or in the extramental world (e.g., God), and (2) the category of the objects that are attached to specific kinds of matter either in the mind or in the extramental world (e.g., human ${ }^{12}$ ). The former objects must be studied by metaphysics and the latter by physics (or natural science). So we have a hierarchy of objects whose degrees of association with (or dependency on) matter vary ${ }^{13}$. According to a wellknown Aristotelian principle which Avicenna endorses, different types of objects must be perceived by distinct cognitive faculties (quwwa in Arabic or dunamis in Greek) or senses ${ }^{14}$. As a result, the cognitive fac-

ical [objects] absolutely do not dispense with matter, even though they can do with some kind of matter" (Marmura's translation, my emphasis). So the dependency of geometrical objects on matter is much stronger than that of numbers. Geometrical objects are associated with matter (though not a specific kind of matter) even in definition. In contrast, numbers can in principle be separate from matter. However, they can be studied by mathematics only when they are considered as being material accidents; otherwise, they are subject to metaphysical studies. As I have argued elsewhere, by contrast with geometrical objects which have an ontological dependency on materiality, numbers inasmuch as they are objects of mathematics have an epistemological dependency on matter. See Zarepour, "Avicenna on the nature of mathematical objects."

${ }^{11}$ By contrast, astronomers and opticians (or applied mathematicians in general) consider and study mathematical objects in association with some specific kinds of matter. This issue has been discussed in detail by Avicenna, The Physics of the Healing, ed. and trans. Jon McGinnis (Provo, 2009), chap. I.8.

12 Humanness, in either the mental or the extramental realms, is attached to a specific kind of matter, i. e., flesh and blood. In other words, humanness separated from flesh and blood does not exist either extramentally or even mentally, or so Avicenna seems to believe.

13 This hierarchical ontology is discussed by Avicenna in his classification of the sciences. This classification is presented in various places within his writings: see, among others, the "Introduction" (Al-šifă ${ }^{\circ}, A l$-mantị, Al-madhal, eds. Georges C. Anawāti, Maḥmūd al-Hֵudayrī, and Aḥmad Fữād al-Ahwānī (Cairo, 1952), chap. I.2) and The Metaphysics of the Healing (chap. I.1-3). The classification is scrutinized by Michael E. Marmura, "Avicenna on the division of sciences in the Isagoge of his Shif $\bar{a}^{\supset}$," Journal for the history of Arabic science, vol. 4, no. 2 (1980), p. 239-51 and Dimitri Gutas, "Medical theory."

14 This principle, which is in fact a rehabilitation of a Platonic principle, is widely employed by Aristotle in his epistemology. For instance, Aristotle's demarcation of the five external senses, as Sorabji observes, is explicitly based on this principle. See Richard Sorabji, "Aristotle on demarcating the five senses," The philosophical review, vol. 80, no. 1 (1971), p. 55-79. For studies on the reception of the Aristotle's views on the cognitive faculties in the Arabic tradition, see Dag Nikolaus Hasse, 
ulty which plays the pivotal role in the apprehension of mathematical objects differs from the faculties by which we know the two other aforementioned types of objects. To see better the contrast between the functions of these distinct faculties, we should first sketch Avicenna's cognitive psychology ${ }^{15}$.

Following Aristotle, Avicenna divides the faculties of the human soul into three classes: vegetative, animal, and rational ${ }^{16}$. All cognitive facul-

"The Soul's faculties," in Robert Pasnau and Christina Van Dyke (eds.), The Cambridge history of medieval philosophy, 2nd ed. (Cambridge, 2014), p. 305-19, and Taneli Kukkonen, "Faculties in Arabic philosophy," in Dominik Perler (ed.), The faculties: A history (Oxford, 2015), p. 66-96.

15 Avicenna's cognitive psychology is set out in numerous works from almost all the periods of his career. These works include (but are not limited to): (1) The "Compendium on the soul" (Maqāla fì al-nafs calä sunna al-ihhtișār), which is probably Avicenna's first philosophical writing. The original Arabic text of this work and its German translation can be found in S. Landauer, "Die Psychologie des Ibn Sīnā," Zeitschrift der Deutschen Morgenländischen Gesellschaft, vol. 29 (1875), p. 335-418. (2) "Book on the soul" (Kitāb al-nafs) of the "Healing" (Avicenna's De anima: Being the psychological part of Kitāb al-shifā̄o ed. F. Rahman (London, 1959)). Avicenna's most extensive investigation of cognitive psychology is offered in this work. (3) "Book on the soul" of the "Salvation" (Al-nağăt, p. 318-96). Its English translation can be found in Avicenna, Avicenna's Psychology, trans. F. Rahman (London, 1952). (4) The psychological part of "The pointers and reminders" (Al-išārāt wa-l-tanbīhāt bi-šarh $a l-T \bar{u} s \bar{\imath}, A l-t a b \bar{\imath} \bar{\imath} y \bar{a} t$, ed. Sulaymān Dunyā (Cairo: 1957), chap. II.3). For an English translation of this work see Avicenna, Remarks and admonitions: Physics and metaphysics, trans. Shams Inati (New York, 2014), p. 94-115. (5) "On the rational soul" (Fì al-nafs al-nătiqa), which is probably Avicenna's last philosophical writing. The original Arabic text of this essay can be found in Avicenna, Ahwwāl al-nafs: Risāla fi al-nafs wa baq $\bar{a}^{\top} i h \bar{a}$ wa ma $a^{c} \bar{a} d i h \bar{a}$, ed. Ahmad Fūād Al-Ahwānī (Cairo, 1952), 19599. An English translation of this essay can be found in Dimitri Gutas, Avicenna and the Aristotelian tradition, 2nd ed. (Leiden, 2014) p. 67-75. Setting aside some minor variations regarding the precise functions of the internal faculties of the animal soul (which I shortly introduce), Avicenna's treatment of the faculties of the soul by and large remains consistent over time. The main tenets of his psychological theory are explained by, among others, Robert E. Hall, "Intellect, soul and body in Ibn Sīnā: Systematic synthesis and development of the Aristotelian, Neoplatonic and Galenic theories," in Jon McGinnis and David C. Reisman (eds.),Interpreting Avicenna: Science and philosophy in medieval Islam, proceedings of the second conference of the Avicenna Study Group (Leiden, 2004), p. 62-86, and Jon McGinnis, Avicenna (Oxford, 2010), chap. 4-5.

${ }^{16}$ Avicenna, Avicenna's De anima, Preface, p. 1-3. This does not however mean that the human soul is not simple (basit $)$. The different faculties of the soul should not be considered as its mereological parts. They are different manifestations, powers or potentialities of a simple unity. For a meticulous analysis of Avicenna's ontology of the human soul, see Seyed N. Mousavian and Seyed Hasan Saadat Mostafavi, "Avicenna on the origination of the human soul," Oxford studies in medieval philosophy, vol. 5 (2017), p. 41-86. 
ties belong to either the animal or the rational soul ${ }^{17}$. In addition to the five familiar external ( $z \bar{a} h i r \bar{\imath}$ ) faculties (or senses) by which we grasp the forms (suwar) of the particulars existing outside of us, Avicenna recognizes five internal $(b \bar{a} t i n \bar{\imath})$ faculties for the animal soul ${ }^{18}$. These faculties are all bodily and located in the various parts of the brain. So their objects cannot be fully separate from matter. Immaterial objects (or, more precisely, objects that are completely disassociated from matter, e.g., God) can be perceived solely by the rational soul. The most obvious example of the objects perceptible to the animal soul are sensible forms. They are the objects of the external faculties in a direct sense. But they can also, in an indirect sense, be the objects of some internal faculties. Put otherwise, the sensible forms perceived by the external faculties can be conveyed to some internal faculties so as to be subject to some further cognitive processes. So sensible forms are accessible to the internal faculties indirectly and through the mediation of the external faculties. This does not imply, however, that the domain of the objects of the internal faculties is restricted to the sensible forms. There are some nonsensible attributes or properties of particular physical objects existing in the extramental world to which the external faculties have no access, or so Avicenna argues. He calls such attributes "connotational attributes" $\left(m a^{c} n \bar{a}^{19}\right)$. For example, the hostility of a wolf is a non-sensible conno-

17 The animal soul has both cognitive and non-cognitive powers. For example, volitional motion is one of the non-cognitive powers of the animal soul.

18 Avicenna, Avicenna's De anima, chap. IV.1. In this context, Avicenna uses "faculty" (quwwa) and "sense" (hiss) interchangeably.

${ }^{19} M a^{c} n \bar{a}$ is sometimes translated as "intention" in the contemporary scholarship. See, among others, Marina Paola Banchetti-Robino, "Ibn Sīnā and Husserl on intention and intentionality," Philosophy East and West, vol. 54, no. 1 (2004), p. 71-82; Deborah L. Black, "Estimation (wahm) in Avicenna: The logical and psychological dimensions," Dialogue, vol. 32, no. 2 (1993), p. 219-58, and "Intentionality in medieval Arabic philosophy," Quaestio, vol. 10 (2010), p. 65-81; Jari Kaukua, Avicenna on subjectivity: A philosophical study (Jyväskylä, 2007); Kukkonen, "Faculties in Arabic philosophy;" and McGinnis, "Experimental thoughts." This translation is inspired by the Latin tradition in which $m a^{c} n \bar{a}$ is translated as intentio. Hasse has argued, convincingly in my opinion, that for Avicenna $m a^{c} n \bar{a}$ is the object of perception; so it cannot be in the perceiver. But intention is something that belongs to the perceiver. Thus "intention" is not an appropriate translation for $m a^{c} n \bar{a}$. He then suggests "connotational attribute" as a more plausible alternative translation. See Dag Nikolaus Hasse, Avicenna's De anima in the Latin West (London, 2000), sec. II.4 (especially p. 132). It is not clear, however, why Hasse decided to resume using "intention" as the translation of $m a^{c} n \bar{a}$ in his "The soul's faculties." For another argument on why "intention" is a misleading translation in this context, see Appendix (3) of Gutas's "The empiricism of Avicenna." In this paper, I consider "meaning” and "connotational attribute" as the equivalents of $m a^{c} n \bar{a}$. 
tational attribute that actually exists in the wolf but cannot be known by a sheep (or even us) merely through sense perception and without the aid of any internal faculty. Undoubtedly, perceiving at least some sensible properties of the wolf (e.g., its color, smell, howl, etc.) is necessary for perceiving its hostility. But the awareness of hostility cannot be automatically derived from the mere perception of such sensible properties. It is the operation of an internal faculty upon the sensible data that makes hostility available/perceptible to the animal soul. Generally, the internal faculties grasp connotational attributes of physical objects by operating upon the information they receive from the external faculties. In sum, connotational attributes are exclusive objects of the internal faculties; but they cannot be known without the effective operation of the external faculties. As Avicenna says:

Texт 1. There is difference between the perception of form and the perception of connotational attribute. Form is something that is perceived by both the internal sense and the external sense. But the external sense perceives it first and then delivers it to the internal sense. This is like the case of the sheep's perception of the form of the wolf - i.e., of its shape, configuration $\left(h a y^{\circ} a\right)$, and color. The internal sense of the sheep perceives it [i.e., the form of the wolf], but it is first perceived by its [i.e., the sheep's] external sense. By contrast, the connotational attribute is something that the soul perceives from the sensible ( $a l$-mahsūs) without the external sense first perceiving it. This is like the case of the sheep's perception of the connotational attribute of enmity [existing] in the wolf or of the connotational attribute that causes the sheep to fear and escape from the wolf. [The sheep perceives these things] without the [external] sense first perceiving them ${ }^{20}$.

According to Avicenna, connotational attributes really exist in the extramental world. They are not mere productions of the mind by a mechanism like abstraction (tajrìd). They are not purely mental constructions. They have actual existence in the extramental world as properties and attributes attached to material objects. Since these attributes are nonsensible, they cannot be perceived by the external faculties. They are objects of the internal faculties. These faculties, however, cannot perceive the connotational attributes of a particular object unless they have already perceived (at least) some sensible attributes of the object. So it seems plausible to say, albeit metaphorically, that the internal faculties perceive connotational attributes through the lens of the external facul-

${ }^{20}$ Avicenna, Avicenna's De anima, chap. I.5, p. 43. Unless otherwise specified, all translations are mine. As we see in the foregoing passage, Avicenna sometimes uses the single form "sense" or "faculty" to refer to a plurality of (either internal or external) faculties or senses. 
ties $^{21}$. How is this possible?

To answer the above question Avicenna develops an extensive theory of five internal faculties ${ }^{22}$. The first of these faculties is the "common sense" (hiss muštarak) which is a receptive faculty placed in the anterior ventricle of the brain. This faculty receives the forms of the sensible particulars from the external senses and processes these inputs to produce phenomenally unified perceptual experiences. In other words, the common sense is the main faculty responsible for sense-perception. The storehouse of the forms and images perceived by the common sense is the second internal faculty: the "form-bearing" (mussawira) or "imagery" ( $h a y \bar{a} l$ ) faculty. This retentive faculty is located behind the anterior ventricle of the brain. In addition to the images and forms perceived by the common sense, the imagery faculty stores the images and forms constructed or created by the operation of another internal faculty called "imagination" (mutahayyila). This faculty is located at the medial ventricle of the brain and its main function is to operate on forms and connotational attributes by shuffling, separating, and recombining them to create new mental entities (i.e., images or forms) that (at least some of them) have no counterpart in the extramental world. So fictional beings, e.g., a phoenix, are constructed by the faculty of imagination ${ }^{23}$. By contrast with the imagery faculty which has only a passive storage function, imagination can actively engage with forms, images and con-

${ }^{21}$ As we will see in the next section, the aforementioned construal of (1) the ontological status of connotational attributes and (2) the epistemic channels via which we can know them is a key to unravel the mechanism of forming mathematical concepts in Avicenna's epistemology.

${ }^{22}$ For a discussion of the epistemological roles of the internal faculties, see Dimitri Gutas, "Intellect without limits: The absence of mysticim in Avicenna," in Maria Cândida Pacheco and José Francisco Meirinhos (eds.), Intellect and imagination in medieval philosophy (Turnhout, 2006), vol. 1, p. 351-72. A comprehensive study on the internal faculties in the Latin, Arabic, and Hebrew traditions is offered by Harry Austryn Wolfson, "The internal senses in Latin, Arabic, and Hebrew philosophic texts," Harvard theological review, vol. 28, no. 2 (1935), p. 69-133.

${ }^{23}$ Avicenna's sophisticated treatment of the ontology and the epistemology of fictional beings is studied by Deborah L. Black, "Avicenna on the ontological and epistemic status of fictional beings," Documenti e studi sulla tradizione filosofica medievale, vol. 8 (1997), p. 425-53, and Thérèse-Anne Druart, "Avicennan troubles: The mysteries of the heptagonal house and of the phoenix," Tópicos, vol. 42 (2012), p. 51-73. Considering the theories propounded between the eleventh and thirteenth centuries in the Islamic tradition, Fedor Benveich has discussed the problem of non-existent objects of thought in a broader historical context. See his "The reality of the nonexistent object of thought: The possible, the impossible, and the mental existence in Islamic philosophy (eleventh-thirteenth centuries)," Oxford studies in medieval philosophy, vol. 6 (2018), p. 31-61. 
notational attributes received from other internal faculties. The intellect can employ imagination and control its function to serve the mechanism of thinking. It is exactly because of this application that imagination is also called the "cogitative" (mufakkira) faculty ${ }^{24}$. The fourth internal faculty is "estimation" (wahm), which is the chief perceiver of connotational attributes in the animal soul. The physical position of this faculty in the brain is the back of medial ventricle. Estimation is a multifunctional faculty that can also contribute in making certain judgments and causing certain actions. In all animals other than the human estimation is the most superior cognitive faculty. It governs and guides all the cognitive faculties of animals which lack a rational soul and is the source of almost all of their actions ${ }^{25}$. It is estimation that enables us to perform thought experiments and to mentally implement scenarios that are unrealizable in the actual world ${ }^{26}$. The fifth and final internal faculty is memory ( $h \bar{a} f i z a)$. This faculty, located at the posterior ventricle of the brain, retains what is perceived or judged by the estimative faculty. So all perceived connotational attributes and all estimative judgments are stored in memory. These five internal faculties intercommunicate with each other by sending and receiving images, forms, connotational attributes, and some specific propositions that are judged to be true ${ }^{27}$.

24 This faculty also plays a remarkable role in the mechanism of revelation. For detailed analyses of different functions of the cogitative faculty, see Deborah L. Black, "Imagination and estimation: Arabic paradigms and Western transformations," Topoi, vol. 19, no. 1 (2000), p. 59-75, and "Rational imagination: Avicenna on the cogitative power," in Luis Xavier López-Farjeat and Jörg Alejandro Tellkamp (eds.), Philosophical psychology in Arabic thought and the Latin aristotelianism of the thirteenth century (Paris, 2013), p. 59-81; and Gutas, "Intuition and thinking" and "Intellect without limits."

25 Avicenna, Avicenna's De anima, chap. IV.1, 167. For example, estimation is responsible not only for the sheep's perception of the wolf's hostility, but also for determining the sheep to flee from the wolf's potential threat. Estimation can in principle contribute to making some judgments, but it is not always reliable and some of its judgments are false. That every existence must occupy space is an example of the false judgments of estimation, or so Avicenna (Al-nağăt, p. 116) contends. For studies on various aspects of the role of estimation in Avicenna's psychology see Black, "Estimation (wahm) in Avicenna" and "Imagination and estimation;" Robert E. Hall, "The wahm in Ibn Sīnā's psychology," in Maria Cândida Pacheco and José F. Meirinhos (eds.), Intellect and imagination in medieval philosophy (2006), vol. 1, p. 533-349; and Kaukua, Avicenna on subjectivity, chap. 3.

26 The functions and applications of thought experiments in Avicenna's philosophical system, and the cognitive capacities we must have to be able to carry out such experiments, are studied by Taneli Kukkonen, "Ibn Sīnā and the early history of thought experiments," Journal of the history of philosophy, vol. 52, no. 3 (2014), p. 433-59, and McGinnis, "Experimental thoughts." 
The harmonic performance of the internal faculties prepares the rational soul (or, more precisely, the intellect) to grasp universal concepts (or intelligibles) and to assent to the truth of universal propositions. The internal faculties bridge the gap between the material world and the immaterial intellect, and make the former apprehensible to the latter, albeit indirectly and through a step-by-step abstraction procedure ${ }^{28}$.

Depending on the four stages of the formation (or, more precisely, perfection) of the intellect, the cognitive power of the rational soul can be manifested in different degrees. These stages are respectively called: (1) "the material intellect ${ }^{29 " ~(~}{ }^{c} a q l$ hay $\left.\bar{l} \bar{a} n \bar{\imath}\right)$ or "the potential intellect" ( ${ }^{c} a q l$ bi-l-quwwa), (2) "the dispositional intellect" ( ${ }^{c} a q l$ bi-l-malaka), (3) "the actual intellect" ( $\left.{ }^{c} a q l b i-l-f{ }^{c} l\right)$, and (4) "the acquired intellect" ( ${ }^{c} a q l$ mustafād). Although the material intellect has absolute potentiality to be impressed by any intelligibles, it has no actual cognitive content; it has not yet perceived anything. The first instances of knowledge im-

27 This brief report is mainly extracted from Avicenna, Avicenna's De anima, chap. IV.1.

${ }^{28} \mathrm{My}$ discussion in this paper is neutral with respect to different readings of Avicenna's theory of abstraction. Some scholars defend an emanationist reading according to which universal knowledge is, in the end, emanated from the Active intellect ( ${ }^{c} a q l$ $f a^{c c} \bar{a} l$ ). See, for example, Nuseibeh, "Al-caql al-qudsi;" Herbert A. Davidson, Alfarabi, Avicenna, \& Averroes, on intellect (Oxford, 1992), chap. 4; Lenn Evan Goodman, Avicenna, updated ed. (London, 2006); and Deborah L. Black, "How do we acquire concepts? Avicenna on abstraction and emanation," in Jeffrey Hause (ed.), Debates in medieval philosophy: Essential readings and contemporary responses (New York, 2014), p. 126-44. Some other scholars support a strongly abstractionist view according to which the epistemic role of the Active intellect is downgraded, and its function is limited to being merely the ontological reservoir of intelligible concepts and propositions. See, for example, Dag Nikolaus Hasse, "Avicenna on abstraction," in Robert Wisnovsky (ed.), Aspects of Avicenna (Princeton, 2001), p. 39-72, and Gutas, "The empiricism of Avicenna." McGinnis, D'Ancona, and Ogden have propounded thoughtprovoking syntheses of these two antithetic approaches. See Jon McGinnis, "Making abstraction less abstract: The logical, psychological, and metaphysical dimension of Avicenna's theory of abstraction," Proceedings of the American Catholic Philosophical Association 80 (2007), p. 169-83; Cristina D'Ancona, "Degrees of abstraction in Avicenna: How to combine Aristotle's De anima and the Enneads," in Simo Knuuttila and Pekka Kärkkäinen (eds.), Theories of perception in medieval and early modern philosophy (Dordrecht, 2008), p. 47-71; and Stephen R. Ogden, "Avicenna's emanated abstraction," Philosophers' imprint, vol. 20, no. 10 (2020), p. 1-26. Compared to D'Ancona, McGinnis and Ogden are more sympathetic to the abstractionist camp.

29 This labelling highlights an analogy between the prime matter and the intellect in its first stage. Like the prime matter that is pure potentiality and has yet to be impressed by the material forms, the material intellect is pure potentiality to receive intelligibles (or universal forms) and has no content of its own. Describing the intellect as being material does not mean that it is constituted from matter. 
pressed upon the intellect are certain primary intelligibles ( $m a^{c} q u l \bar{a} t$ ${ }^{\circ} \bar{u} l \bar{a}$ ) our knowledge of which is not grounded in the acquisition of other concepts and propositions. The intellect inasmuch as it has perceived only the most fundamental instances of universal knowledge is called "the dispositional intellect." That the whole is greater than the part is an example of such basic propositions whose truth is assented to by the dispositional intellect. More sophisticated sorts of knowledge that are not restricted to the laws of thought and logical tautologies and actually inform us about the substantial facts of the world will be obtained in the next step of the actualization of the intellect. Almost all kinds of universal knowledge (either conceptual or propositional) that we can in principle obtain are present (and, in a sense, stored) in the actual intellect. At this stage the intellect has the potentiality of consciously entertaining all of these instances of knowledge. But this potentiality is activated only in the fourth and final stage of the perfection of the rational soul where the acquired intellect consciously considers and entertains the intelligibles that are possessed by the dispositional and the actual intellects. Avicenna contends that, at this stage, the intellect has even a second-order consciousness of what it is doing. Not only does it consciously engage with the intelligibles, but it is also conscious of doing so $^{30}$.

With these rough and ready portraits of Avicenna's ontology of mathematics, on the one hand, and of his cognitive psychology, on the other, we are well equipped to tackle his account of how we grasp mathematical concepts.

\section{FORMING MATHEMATICAL CONCEPTS}

As I clarified in the previous section, Avicenna believes that mathematical objects are specific properties of physical particular objects that can - and many of them actually do - exist in the extramental world. It is not surprising, therefore, that he denies the possibility of grasping mathematical concepts without appealing to any perceptual experiences. In his criticisms of mathematical Platonism in The Metaphysics of the Healing, he says:

TEXт 2. If among mathematical things there is a mathematical object separate from the sensible mathematical object (al-taclìmi al-mahsūs) at

30 This brief description of the stages of the perfection of the intellect is extracted from Avicenna, Avicenna's De anima, chap. I.5, p. 48-50. See also Avicenna, Ahwāl al-nafs, p. $195-6$. 
all, then in the sensible thing either there would be no mathematical object or there would be [a mathematical object]. If in the sensible thing ( $f i$ al-mahsūs) there is no mathematical object $\left(t a^{c} l \bar{\imath} m \bar{\imath}\right)$, then it necessarily follows that there is no quadrilateral, circular, or numbered $\left(m a^{c} d \bar{u} d\right)$ sensible thing. If none of [these things] is sensible, then what way is there to establish their existence [or], indeed, [even] to imagine them? For the principle of their being imagined is likewise [derived] from sensible existence - so much so that, if we suppose, through our estimative faculty, an individual who has apprehended none of [these] by the senses, we will judge that he does not imagine, nor, indeed, intellectually apprehend any of them. However, we have established the existence of many (katīr) of them in what is sensible ${ }^{31}$.

Here Avicenna is proposing a thought experiment that is structurally very similar to the Flying Man argument ${ }^{32}$. Indeed, it can be considered as a brief version of the Flying Man argument restricted to the context of the epistemology of mathematics. The experiment goes as follows: Suppose an individual who, for some reason, has no apprehension of the mathematical objects existing in the sensible world. Such an individual would have neither any imagination (tahayyul) nor any intellectual apprehension ( $\left.t a^{c} a q q u l\right)$ of mathematical objects (e.g., quadrilaterals and circles), or so Avicenna claims. But almost all individuals can imagine and intellectually apprehend some mathematical objects. This indicates, Avicenna seems to believe, not only that (at least some) mathematical objects actually exist in the sensible world, but also that perceiving such objects is a prerequisite for having any imagination or intellectual apprehension of mathematical shapes ${ }^{33}$. Avicenna here does not say anything about assenting to the truth of mathematical propositions. It seems therefore that he merely wants to highlight a

${ }^{31}$ Avicenna, The Metaphysics of the Healing, chap. VII.3, sec. 1. I have slightly revised Marmura's translation by replacing "numerable" with "numbered" as the translation of $m a^{c} d \bar{u} d$. Phrases in brackets are added by him. The passage quoted here is part of an extended argument against the existence of mathematical objects that are fully separate ( $m u f \bar{a} r a q)$ from matter. I have elsewhere discussed the subtleties of that argument. See Zarepour, "Avicenna against mathematical Platonism."

32 For studies on the logical structure and the philosophical consequences of the Flying Man argument see, among others, Michael E. Marmura, "Avicenna's 'Flying Man' in context," The Monist, vol. 69, no. 3 (1986), p. 383-95; Ahmed Alwishah, "Ibn Sīnā on floating man arguments," Journal of Islamic philosophy, vol. 9 (2013), p. 49-71; and Peter Adamson and Fedor Benevich, "The thought experimental method: Avicenna's Flying Man argument," Journal of the American Philosophical Association, vol. 4, no. 2 (2018), p. 147-64.

${ }^{33}$ See Avicenna, Al-burhān, chap. III.5, p. 220 where, discussing Aristotle's Posterior analytics I.18, Avicenna claims that our knowledge of mathematical objects (e. g., triangles) - like many other instances of knowledge - is obtained through the mediation of sense perception. 
crucial point specifically about the formation of mathematical concepts. More precisely, the thought experiment is apparently intended to show that grasping mathematical concepts (which are objects of the intellect and intellectual apprehension) is impossible unless we first have specific perceptual experiences. The passage affirms that Avicenna embraces a modest version of concept empiricism regarding mathematics. I qualified my statement with the adjective "modest" since the above passage does not deny the possible contribution of a further rational or emanational element (e.g., the Active intellect) in the process of the formation of mathematical concepts. That forming a mathematical concept (e.g., the concept "circle") depends heavily on having some perceptual experiences (e.g., seeing a circular object) does not entail that necessarily mathematical concepts are constructed rather than emanated. Receiving data through the perceptual experiences might be only a subsidiary step for the preparation of the intellect to receive the universal concepts emanated by the Active intellect. But in any case - whether or not the emanationist account is defensible - the significant conclusion of this passage is that mathematical concepts are neither innate nor given at birth. They cannot be grasped unless we have some a posteriori perceptions. This reading of Avicenna's account of the formation of mathematical concepts is perfectly compatible with Gutas's general claim that for Avicenna all concepts are derived eventually from what we perceive by our external senses ${ }^{34}$.

It is still not clear which cognitive faculties play the pivotal role in grasping mathematical concepts. Mathematical objects are specific properties or attributes of physical objects and, as the above passage witnesses, they cannot be known unless we receive some data through our sense perceptions. Nonetheless, it is still not clear whether or not mathematical objects are themselves sensible. As we saw in the previous section, according to Avicenna, not only sensible attributes but also non-sensible connotational attributes of physical objects cannot

${ }^{34}$ See Gutas, "The empiricism of Avicenna.” Gutas's general claim about all concepts entails my analysis which is restricted to the scope of mathematical concepts; but the other way around does not hold. By contrast with Gutas, I am reluctant to surmise that Avicenna's empiricism is extensible to all concepts. Avicenna is not an empiricist about all instances of (either conceptual or propositional) knowledge, or so I have argued in my "Avicenna's notion of fitrīyāt: A comment on Gutas's interpretation," Philosophy East and West, vol. 70, no. 3 (2020), p. 819-33. See also Gutas's reply to my note and my rejoinder to him: Dimitri Gutas, "The myth of Kantian Avicenna," Philosophy East and West, vol. 70, no. 3 (2020), p. 833-40, and Mohammad Saleh Zarepour, "Non-innate a priori knowledge in Avicenna," Philosophy East and West, vol. 70 , no. 3 (2020), p. 841-48. 
be perceived if we lack sense perception. In fact, our knowledge of the connotational attributes of physical particulars is indirectly extracted by the faculty of estimation from the data transferred from the faculty of common sense. So the fact that the lack of sense perception results in the lack of mathematical concepts does not on its own show that mathematical objects are themselves sensible attributes. Avicenna's language regarding the exact ontological status of mathematical objects is obscure and equivocal. Although he has never denied that they can exist in the actual world as properties or attributes of sensible particular objects, it is not crystal clear whether or not he considers these properties to be sensible.

There are passages that might be taken as evidence that mathematical objects are sensible (mahsūs); i. e., they are perceived by the external senses. For example, in the previous passages, Avicenna explicitly states that there are sensible mathematical objects. Moreover, in other places, he mentions shapes and numbers in the list of common sensibles $^{35}$ (al-mahsūsāt al-muštaraka). Common sensibles cannot be directly perceived by any external senses. They are grasped by the mediation of some sensibles that are themselves the direct objects of the external senses. To give an example, the direct objects of the sense of taste are flavors. Thus numbers cannot be directly perceived by the sense of taste. Numbers are not tastable. Nonetheless, the sense of taste can perceive numbers through the mediation of different flavors. It can grasp the numerosity of the different flavors one might taste. So when I am eating a mixed fruit salad, the flavors of the fruits are directly perceived by the sense of taste; but the number of the different flavors I am tasting is perceived only indirectly and through the mediation of those flavors. By tasting and distinguishing the different flavors of the fruits of the salad, the sense of taste enables me to realize that I am experiencing, for example, three distinct flavors. However, the number three itself is not tastable. Similarly, although the twoness of the two books I see on my desk is not directly seeable, it can be indirectly perceived by the sense of vision through the meditation of the colors and shades of the books ${ }^{36}$. Based on these observations, one might be inclined to conclude that for Avicenna the objects of mathematical studies are perceived, at worst indirectly, by the external senses. However, this account of the nature of mathematical objects seems untenable for several reasons.

${ }^{35}$ See, among other places, Avicenna, Avicenna's De anima, chap. I.4, p. 34-5 \& chap. III.8, p. 159-60.

${ }^{36}$ According to Avicenna, only colors are directly and immediately seeable. 
As I clarified in section two, mathematical objects are detached from all particular matters but still associated with materiality itself. Mathematicians consider objects as being detached from any specific colors, flavors, sounds, etc. Numbers and shapes - inasmuch as they are subject to pure mathematical studies - have none of such sensible properties. By contrast, the presence of these properties is necessary for the perception of the common sensibles through the indirect function of the external senses. Common sensibles cannot be perceived in the absence of the sensible properties that are the direct objects of the external senses ${ }^{37}$. More precisely, the external senses (like imagination) cannot remove the attachment of the objects of perception to the specific kinds of matter. Since the external senses do not engage in any degree of dematerialization, they perceive numbers and shapes in association with determinate kinds of matter. Accordingly, it cannot conceive numbers and shapes in the way that mathematicians consider them. Put otherwise, although numbers and shapes indirectly perceived by the external senses are associated with specific kinds of matter, numbers and shapes studied in pure mathematics are completely free from such an association. Therefore, numbers and shapes - inasmuch as they are objects of mathematics - should be perceived by another faculty ${ }^{38}$. My suggestion is that the objects of pure mathematics should be apprehended by the faculty of estimation.

The above suggestion is supported by Avicenna's frequent references to the role of estimation in grasping mathematical concepts. For example, in his discussions of the ontological status of the objects of different scientific disciplines in "Introduction" of the "Healing," Avicenna says:

Texт 3. The things that mix with motion are of two kinds. They are either such that they have no existence unless they undergo admixture with motion, as for example, humanness, squareness and the like; or they have existence without this condition. The existents that have no existence unless undergoing admixture with motion are of two divisions. They are either such that, neither in subsistence nor in the "estimation" (wahm) would it be true for them to be separated (tujarradu) from some specific matter as for example, the form of humanness and horseness; or else, this would be true

${ }^{37}$ See Avicenna, Avicenna's De anima, chap. III.8, p. 161-2.

${ }^{38}$ To give an example, mathematics studies the twoness of two material things regardless of all other characteristics that those things might have. But the external senses cannot consider numerosity in isolation from proper sensibles. For example, the sense of vision can perceive the twoness of two books on my desk. But in such a perception the twoness is considered in association with the colors of those books. Such a consideration is by no means mathematical. See Avicenna, The Physics of the Healing, chap. I.8., sec. 3. 
for them in the "estimation" but not in subsistence, as for example, squareness. For, in the case of the latter, "conceiving it" (tașawwuruhū) does not require that it should be given a specific kind of matter or that one should pay attention to some state of motion ${ }^{39}$.

It seems quite defensible to think that Avicenna's description of the ontological and epistemological status of squareness is uncontroversially generalizable to all geometrical objects. If so, geometrical objects actually exist in the sensible world in association with some specific kinds of matter. By the act of the faculty of estimation (bi-l-tawahhum) we can separate them from those specific kinds of matter they are attached to in the extramental realm ${ }^{40}$. This enables us to conceive the concepts of geometrical objects free from any particularized association with matter, in exactly the same way as we entertain geometrical concepts in practicing pure geometry ${ }^{41}$. Estimation plays a somewhat analogous role in conceiving numbers. In his analysis of numbers in the "Introduction" of the "Healing" Avicenna says:

Text 4. [An] accident, even though it cannot occur except in relation to matter and mixed with motion, [might be] such that its state can be apprehended by the "estimation" and discerned without looking at the specific matter and motion [it is attached to]. An example of this would be addition and subtraction, multiplication and division, determining the square root and cubing, and the rest of the things that append (talhaqu) to number. For all this attaches to number either in men's faculty of "estimation," or in the existents that are subject of motion, division, subtraction and addition. Conceiving its concept, however, involves a degree of abstraction that does not require the specifying of matters of certain species ${ }^{42}$.

Another passage of the same spirit can be found in The Metaphysics of the Healing:

${ }^{39}$ Avicenna, Al-madhal, chap. I.2, p. 12-3. I have borrowed this translation, with some modification, from Marmura, "Avicenna on the division of sciences." The emphases are mine.

40 See Avicenna, The Metaphysics of the Healing, chap. III.4., sec. 2. There Avicenna says that magnitude (miqdār), which is the subject matter of geometry and can be interpreted as the most general representative of geometrical objects, "does not separate from matter except in the act of estimation" (Marmura's translation).

41 This does not however mean that we can conceive geometrical shapes as entities independent from matter and materiality in general. Avicenna (The Metaphysics of the Healing, chap. VII.2., sec. 21) insists that even the definitions (hudūd) of geometrical objects "do not utterly dispense with matter, even though they can do with any given species of matter" (Marmura's translation, modified). So even in the faculty of estimation geometrical shapes are considered as properties of material entities.

42 Avicenna, Al-madhal, chap. I.2, p. 13-4. I have taken this translation, with some modification, from Marmura, "Avicenna on the division of sciences." 
Text 5. The science of arithmetic, inasmuch as it considers number (yanzuru fi al- ${ }^{c} a d a d$ ), considers it only after [number] has acquired that aspect possessed by it when it exists in nature ( $\left.f \grave{i} a l-t a b \bar{\imath}^{c} a\right)$. And it seems that the first consideration [or theoretical study] of [number that the science of arithmetic undertakes] is when it is in the estimative faculty having the description [mentioned] above; for this is an estimation [of number] taken from natural states subject to addition and subtraction and unification and division $^{43}$.

Number can be studied by arithmetic only if it is subject to addition, subtraction, etc. But number is subject to these accidents only when it is in the nature ${ }^{44}$ (i. e., in the sensible world). In other word, number inasmuch as it is the subject matter of arithmetic should be attached to matter. So the object of arithmetic exists in the sensible world. However, from a purely mathematical point of view, the specific kind of matter with which number is mixed in the sensible world has no significance. Mathematicians perceive number as something attached to matter but without any particularized association with any specific kind of matter. To conceive the concepts of numbers, mathematicians look at numbered things ( $\left.m a^{c} d \bar{u} d \bar{a} t\right)$ in the sensible world and overlook all of their particularized (and mathematically unimportant) features. It is only the faculty of estimation which bestows this ability to human beings, or so Avicenna seems to believe. This means that the objects of pure mathematics are, in the first place, the objects of estimation. As we know, following the common tradition, Avicenna calls the objects of estimation "connotational attributes ${ }^{45}$." Therefore, mathematical objects should be considered as connotational attributes of the sensible objects existing in the physical world.

This construal of the ontological status of mathematical objects is reinforced by Avicenna's description of mathematical objects as existents in the sensible things ${ }^{46}$ ( $f \grave{\imath}$ al-mahsūsât). This terminology is what

${ }^{43}$ Avicenna, The Metaphysics of the Healing, chap. I.3., sec. 18. I have revised Marmura's translation.

${ }^{44}$ By contrast with geometrical objects, number can in principle be fully separate from matter. However, fully immaterial number is not subject to mathematical accidents and should be studied by metaphysics, rather than arithmetic. Thus even in the faculty of estimation, numbers - inasmuch as they are subject to mathematical studies - should be considered as properties of material entities. In this latter respect, there is no difference between numbers and geometrical shapes. See Avicenna, Al-madhal, chap. I.2, p. 14, and The Metaphysics of the Healing, chap. I.3., sec. 20.

45 Avicenna (Avicenna's De anima, chap. IV.1, p. 167) says: "It is a common tradition to call what is perceived (mudrak) by the [common] sense (al-hiss) as 'form' (süra) and what is perceived by the estimation $(a l-w a h m)$ as 'connotational attribute' $\left(m a^{c} n \bar{a}\right)$. ." 
Avicenna usually employs to refer to connotational attributes ( $\left.m a^{c} \bar{a} n \bar{\imath}\right)$, which are, as we saw in the previous section, non-sensible. For instance, in The Salvation Avicenna describes estimation as a faculty which perceives "non-sensible connotational attributes existing in the sensible particulars ${ }^{47 "}($ al-macōnī al-ghayr al-mahsūsa al-mawjūda fì al-mahsūsāt $a l$-juz $\left.z^{\supset} y a\right)$. Accordingly, it seems plausible to think that mathematical objects - which are described as existing in the sensible things - are non-sensible connotational attributes of those things.

The mechanism of forming mathematical concepts is usefully comparable to that of the concept of hostility. Hostility is a connotational attribute of certain sensible existents like wolves. Although it actually exists in the sensible world, it is not itself sensible. To perceive hostility we should first have a sense perception of a sensible thing in which this attribute exists. For instance, we should see a wolf (hopefully from a safe distance!) and perceive its sensible attributes (e. g., its color, smell, howl, etc.). The data collected by our external senses will be transferred to the faculty of estimation (through the faculty of common sense). Finally, we can perceive the hostility of the wolf by our estimation. In fact, estimation can extract something from the received data that is not perceivable to the external senses. It is true that our apprehension of hostility has been formed through having a sense perception of a wolf. But our estimation enables us easily to overlook all other characteristics of the experience we have had, and to consider the property of being hostile in itself and independently of all other particularized properties of the wolf we have seen. Hostility perceived as such is something that actually exists in the sensible world; it is not merely imagined or mentally constructed. Similarly, mathematical objects really exist in the sensible world. We first perceive the sensible attributes of the particular physical things in which mathematical objects exist. For instance, we perceive a bronze circular plane or a set of two wooden chairs. What we grasp through these perceptual experiences will be given, by the mediation of the common sense, to estimation. Our estimation neglects all mathematically unimportant features of the received data and eventually perceives the circle and the number two that exist in those sensible things. The moral of

${ }^{46}$ For example, in Texт 2, Avicenna argues that mathematical objects must exist in the sensible things. See, in particular, the last sentence of the passage. Similarly, in Texт 4 and Texт 5, Avicenna discusses the existence of numbers, respectively, in the existents that are subject of motion and in nature.

${ }^{47}$ Avicenna, Al-nağāt, p. 329; my emphasis. A similar description is presented in $\mathrm{Al}$ išārāt wa-l-tanbīhāt, $A l$-țabic $\bar{c} y \bar{a} t$, chap. II.3, sec. 9, p. 379. See also Text 1 in which Avicenna says that the connotational attribute of enmity exists "in the wolf." 
this comparison is that (at least some) mathematical objects actually exist in the sensible world and can be perceived by estimation ${ }^{48}$. They are not merely imagined or mentally constructed. Given this interpretation, mathematical objects are some specific non-sensible connotational attributes of sensible objects. Accordingly, when Avicenna talks about sensible mathematical objects (as he does in Texт 2), what he has in mind is the sensible objects in which mathematical objects exist (or, equivalently, of which mathematical objects are connotational attributes). $\mathrm{He}$ does not really mean that mathematical objects, inasmuch as they are considered by pure mathematicians, are sensible.

It is noteworthy that the objects of estimation are not universal concepts. Estimation can perceive the twoness of many different sets of two objects, in exactly the same way that it can perceive the hostility of many different animals. Indeed, it is the repetitious actions of estimation in perceiving various instances of twoness and hostility that prepare the intellect to grasp the universal concepts "two" and "hostility" 49.

So far, I have shown that, according to Avicenna, many mathematical objects exist in the sensible world (as the last sentence of Text 2 assures us) and can be perceived by estimation (as is supported by Texт 3 and TeXT 4) ${ }^{50}$. But many of the complicated geometrical objects that mathematicians work with in Euclidean geometry have no counterpart in the sensible world. They cannot therefore be either sensible or non-sensible attributes of particular material objects. Accordingly, they are objects of neither sense perception nor estimation. So it is necessary to clarify how Avicenna's epistemology accommodates the possibility of engaging

48 This comparison, like any other, has its own limitations. For example, by contrast with hostility which can in principle belong to immaterial things, the objects of mathematics have no existence but in material entities. See Avicenna, The Metaphysics of the Healing, chap. VI.5., sec. 52.

${ }^{49}$ In this paper, I do not touch on the role of the Active intellect in the formation of mathematical concepts. This is because, to the best of my knowledge, there is no textual evidence that the role of the Active intellect in the formation of mathematical concepts differs from its role in the formation of other kinds of concepts. So any defensible account of the role of the Active intellect in the formation of other concepts is extendable to the context of the epistemology of mathematics.

50 There are still other allusions to the role of estimation in grasping mathematical concepts in Avicenna's oeuvre. For example, in The Metaphysics of the Healing, chap. III.4, he argues that although in the extramental realm, point cannot be separated from line, and line cannot be separated from plane, and plane cannot be separated from body, estimation enables us to perform such separations mentally and consider point, line and plane as separate mathematical objects. As another example in the same book, see his reference to the role of estimation in making infinite magnitudes conceivable to the human mind in chap. III.4, sec. 2. 
with non-existent geometrical shapes. Avicenna himself concedes that it is impossible for many geometrical objects to exist in the extramental world. In an abstruse passage of the physics part of "The pointers and reminders" he says:

Text 6. To perceive $\left({ }^{\circ} i d r \bar{a} k\right)$ a thing is that its reality (haqīqa) is represented (mutamattal) to the perceiver, such that the perceiver observes it [i.e., the reality of the perceived thing] by that with which he perceives. It is either that that reality is exactly the reality existing externally to the perceiver when he perceives. [But this cannot be the case because] there might be a reality that has no actual existence in the extramental world; e. g., many (katitr) of the geometrical shapes or many of the impossible things that are posited in geometry but cannot be realized at all. Or a representation (mitâal) of its reality [rather than the reality itself] is impressed (murtasam) on the essence of the perceiver, [a representation that is] not separated from [or external to] him ${ }^{51}$.

This passage is not exclusively related to the epistemology of mathematics. Here Avicenna is arguing that perception cannot be the presence of a concrete object to the perceiver. This is because we are able to perceive non-existent things which have no concrete existence to be presented to other things (e.g., a perceiving agent). Therefore, what is presented to the perceiver should be a representation of the concrete object we perceive, rather than the object itself. What is relevant to our discussion here is that the passage leaves no doubt that many conceivable geometrical objects are not actually exemplified in the sensible world. If those objects existed, they would have been attributes of sensible objects. But they do not exist in the sensible world at all. Consequently, they cannot be perceived by either the external senses or the faculty of estimation. So an immediate natural question raises: how can we conceive such objects?

Before discussing Avicenna's response to this question, I would like to highlight two remarkable points we can extract from this passage. First, Avicenna does not claim that all or most geometrical objects do not exist in the extramental world. He merely says that many (katīir) of them have no concrete existence. It reassures us that any understanding of Avicenna's philosophy of mathematics that renders all geometrical objects as purely mental constructions is wrong. Second, as we saw in Texт 2, Avicenna believes that the existence of many geometrical objects in the sensible world is undeniable. Given the fact that he mentions circle, triangle and square as examples of geometrical objects that actu-

${ }^{51}$ Avicenna, Al-išārāat wa-l-tanbīhāt, Al-țabīc $\bar{\imath} y \bar{a} t$, chap. II.3, sec. 7. 
ally exist in the sensible world, we would expect that he considers some more peculiar geometrical objects as examples of the things that are conceivable but do not exist in the extramental world. This expectation is well supported by al-Tūusìs analysis of this passage. In his commentary on "The pointers and reminders," al-Ṭūsī points out that the geometrical shapes to which Avicenna refers are either (1) things that although they do not currently exist in the extramental world, it is in principle possible for them to come to exist, or (2) things that neither do nor can ever exist in the extramental world. Examples of the latter group are, al-Ṭūsì suggests, impossible things we posit for the sake of a reductio ad absurdum. We can conceive such entities despite the logical impossibility of their actual existence. As an example of the former group, al-Ṭūsī mentions "a sphere in which a pentagonal dodecahedron is inscribed $^{52}$." He has apparently borrowed this example from Avicenna's discussion of universal and particular terms in the logic part ${ }^{53}$ of "The pointers and reminders." There Avicenna introduces the term "spherical shape in which a pentagonal dodecahedron is inscribed" as referring to a universal that does not exist in anything at all, but which could exist in many ${ }^{54}$. So Avicenna seems to believe that although many basic mathematical objects (e. g., some numbers, circle, triangle, and square) actually exist in the sensible world and can be perceived by the faculty of estimation, there are also many more complicated mathematical objects that have no extramental existence ${ }^{55}$. This observation about the overall complexity of non-existent objects of mathematics takes us one step closer to knowing how we conceive such objects.

The complex geometrical shapes that do not actually exist in the sensible world can be decomposed into simpler parts each of which is either a geometrical shape that exists in the sensible world (e. g., a circle or a triangle) or a part of such a shape (e.g., an arc of a circle). So it is quite natural to think that we can conceive the complex geometrical shapes that have no counterpart in the material world through separating, dividing and combining what we have previously perceived from simpler mathematical objects that actually exist in the sensible world. As we saw

${ }^{52}$ Avicenna, Al-išāāāt wa-l-tanbīhāat, Al-țabī ${ }^{c} \bar{\imath} y \bar{a} t$, chap. II.3, sec. 7, p. 361.

${ }^{53}$ Avicenna, Al-išārāt wa-l-tanbīhāt, Al-manțiq, chap. I.1, sec. 8, 149.

${ }^{54}$ Avicenna's motivations for replacing the example of ${ }^{c} a n q \bar{a}^{\supset}$ with this example have been illustrated by Druart, "Avicennan troubles."

55 Avicenna believes that only a finite number of numbers actually exist in the extramental world. For further discussions see Mohammad Saleh Zarepour, "Avicenna on mathematical infinity,” Archiv für Geschichte der Philosophie, vol. 102, no. 3 (2020), p. $379-425$. 
in the previous section, Avicenna nominates a specific cognitive faculty for accomplishing such a mission: imagination. The following passage from "Book on the soul" of the "Healing" summarizes how this faculty enables us to think about non-existent things:

Text 7. We certainly know that it is in our nature to combine part of sensible things with another part and to separate part of them from another part, not according to the form of them we found in the extramental world, nor even with affirming the existence or non-existence of any of them. Thus, there must be a faculty in us by which we perform that. This is what is called the "cogitative" [faculty] when employed by the intellect and "imagination" when employed by the animal faculty ${ }^{56}$.

It is through the act of imagination that we can take what is grasped and stored by other internal faculties to construct some mental artifacts regardless of whether or not they would have any counterpart in the sensible world. By separating and combining different elements of sensible and non-sensible attributes that we have perceived from the material objects existing in the extramental world, we can conceive objects that do not exist but could have existed (e.g., a sphere in which a pentagonal dodecahedron is inscribed or a heptagonal house) or even objects that can never come to exist (e.g., a phoenix) ${ }^{57}$. Definition ( $t^{c}$ rîf or hadd) of a complex geometrical object can be considered as a recipe for imagination to build that object in the mind by combining different elements of the simpler objects mentioned in the definition. Finally, by the intervention of the Active intellect, these mental artifacts are turned into universal concepts and become graspable by the human intellect.

${ }^{56}$ Avicenna, Avicenna's De anima, chap. IV.1, p. 165-6.

57 The example of the heptagonal house is taken from The Metaphysics of the Healing, chap. V.1, sec. 2. Avicenna dealt with the epistemology of non-existent objects in the "Letter on the disappearance of the vain intelligible forms after death." The original Arabic of this letter and its French translation can be found in Jean R. Michot, "L'épître sur la disparition des formes intelligibles vaines après la mort' d'Avicenne," Bulletin de philosophie médiévale, vol. 29 (1987), p. 152-67. An English translation of this letter is provided in Jean Michot, "Avicenna's 'Letter on the disappearance of the vain intelligible forms after death', Bulletin de philosophie médiévale, vol. 27 (1985), p. 94-103. As we saw, in his commentary on Texт 6, al-Ṭūsī refers to impossible hypothetical geometrical shapes posited for the sake of a reductio ad absur$d u m$ and considers them as another example of the non-existent objects of thought. Nonetheless, it seems to be dubious that imagination or the cogitative faculty can conceive such objects. This is because there cannot be any consistent image of them, by contrast with other non-existent objects like phoenix. My suggestion is that such impossible objects are directly posited by the intellect as a collection of universal concepts. However, discussing the details of this proposal is beyond the scope of the present paper. 
In sum, some of the objects of mathematics exist and some do not. Every existing mathematical object is a non-sensible connotational attribute of a physical object and can be perceived by the faculty of estimation. Non-existing mathematical objects can be represented and perceived by the faculty of imagination through separating and combining parts of the images of existing mathematical objects that are previously perceived by estimation. In any case, even non-existing mathematical objects should be considered as properties of material entities. They can never be grasped as fully immaterial entities ${ }^{58}$.

There still remains an important worry about the formation of mathematical concepts. One might say that mathematical objects as considered by mathematicians are so perfect and idealized that they cannot be found in the extramental world. There is no perfect circle in the sensible world such that all points on its circumference are of exactly the same distance from its center. Even if this is not visible to the naked eye, there is no doubt, the complaint might continue, that the circumference of any seemingly circular material object is serrated. There is no real circle in the sensible world. Similarly, there is no perfectly straight line and, consequently, no real square or triangle in the extramental reality. If so, perfect mathematical objects as considered by mathematicians cannot actually exist in the sensible things. Accordingly, they cannot be objects of estimation. So estimation plays, if any, an ancillary role in the formation of mathematical concepts. Since, according to this caveat, all perfect objects have no existence in extramental reality, they should be constructed by imagination. Therefore, it is imagination, rather than estimation, which plays the protagonist in the epistemology of mathematical concepts. This argument, if sound, shows that the core of Avicenna's ontology of mathematics is better captured by a fictionalist-abstractionist account, rather than a literalist one. However, as we will see in the next section, Avicenna denounces this line of argument.

\section{PERCEIVING PERFECT MATHEMATICAL OBJECTS}

As mentioned in the last sentence of Text 2, Avicenna puts forward arguments to establish the existence of some geometrical figures in the sensible world. For example, in The Metaphysics of the Healing, he pro-

${ }^{58}$ Universal mathematical concepts, just like all other concepts, are fully immaterial intelligibles. But this does not mean that mathematical objects can be conceived as immaterial entities. The concept "human" is itself an immaterial intelligible; nonetheless, a human being cannot be conceived as an immaterial entity. 
pounds a complicated argument to show that, contrary to the atomists' view, perfect circles truly exist in the extramental world ${ }^{59}$. Avicenna's report of the atomists' position regarding the existence of the circles goes as follows:

Text 8. If one assumes a circle as a sensible thing ( ${ }^{c} a l \bar{a}$ al-naḥw almahsūs), it being, as they state, not a real circle but [a figure whose] circumference is serrated $^{60}$ (mudarras).

But Avicenna denounces the atomists and claims:

Tехт 9. As for the doctrine of the person who constructs magnitudes from atoms, it would also be possible to prove the existence of the circle against him from his [own] principles. With the existence of the circle, one would then repudiate the existence of atom [to which he subscribes] ${ }^{61}$.

As these two passage explain, Avicenna believes that (1) the atomists deny that a perfect circle can in principle exist in the sensible world, (2) the existence of such a geometrical object can be derived from the principles they endorse, therefore, (3) the atomists' position is self-refuting ${ }^{62}$. It is worth noting that the existence of a quasi-circular object that looks like a perfect circle but has some microscopic deviations in its circumference does not necessarily contradict atomism. An atomist can selfconsistently say that the imperfectness of many geometrical shapes appears only at the atomic level and is not easily detectable by our sense organs. Atomism is an ontological doctrine which cannot be disproved by the mere epistemic fact that some objects look like perfect circles whose circumferences are not jagged or bumpy. So the aim of Avicenna's argument is exactly to establish the existence of perfect circles in the sensible world, rather than merely to confirm that some sensible objects look like a perfect circle. This much suffices to convince us that Avicenna actually believes that perfect mathematical objects literally exist in the sensible world. However, it is worth scrutinizing another passage in which, without providing any argument, Avicenna simply presupposes the existence of certain perfect geometrical shapes in the sensible world to cast doubt on the soundness of atomism. In The Physics of the Healing, he argues:

TexT 10. In fact, the existence of atoms would necessarily entail that there be no circles, right triangles, or many other [geometrical] figures [...]. When two sides of a right triangle are each ten units, then the hypotenuse is

${ }^{59}$ Avicenna, The Metaphysics of the Healing, chap. III.9.

${ }^{60}$ Ibid., chap. III.9, sec. 6. I have revised Marmura's translation.

61 Ibid., chap. III.9, sec. 5 .

62 (1) is true because, according to the atomists, there is no possible non-serrated arrangement of atoms on the circumference of a circle. 
the square root of two hundred, which [according to the present view] would either be an absurdity that does not exist, or it is true, but atoms would be broken up, which [according to the present view] they are not ${ }^{63}$.

Here Avicenna does not provide any argument for the existence of perfectly right triangles. He simply takes it for granted that such triangles could possibly exist. Then, based on this assumption, he advances an argument against atomism which can be formalized as follows:

(1) According to atomism every finite magnitude is constituted of a finite number of indivisible atoms of equal length. Equivalently, for every finite magnitude, there should be a natural number $n$ such that the length of the magnitude is equal to the length of $n$ atoms.

(2) There could possibly exist a right triangle that the length of each side of its right angle is equal to the length of 10 atoms.

(3) According to the Pythagorean Theorem, the length of the hypotenuse of such a right triangle is equal to the square root of the length of 200 atoms.

(4) The square root of 200 is not a natural (or even rational) number $(\sqrt{200}=14.142135 \ldots)$.

(5) There is no natural number $n$ such that the length of the hypotenuse is equal to the length of $n$ atoms.

(6) Either there can be no hypotenuse of a right triangle whose length is equal to the square root of the length of 200 atoms or there can be such a hypotenuse but it is constituted of 14 complete atoms and a broken atom.

(7) If there can be no hypotenuse of a right triangle whose length is equal to the square root of the length of 200 atoms, then (2) is false.

(8) If there can be such a hypotenuse but it is constituted of 14 complete atoms and a broken atom, then (1) is false.

(9) Either (1) or (2) is false.

(10) (2) is obviously true.

Therefore,

(11) (1) is false, and atomism is refuted ${ }^{64}$.

63 Avicenna, The Physics of the Healing, chap. III.4, sec. 5. Apart from the replacement of "parts" by "atoms" in the last sentence, I have been faithful to McGinnis's translation.

${ }^{64}$ In a footnote to his translation of this passage McGinnis has provided a brilliant reconstruction of this argument that slightly differs from mine. See Avicenna, The Physics of the Healing, chap. III.4, sec. 5, p. 285, n. 9. An advantage of my analysis over that of McGinnis's is that, according to my reconstruction, the soundness of Avicenna's argument does not depend on the geometrical configuration of atoms. By contrast, McGinnis's reconstruction is built upon the mutakallimūn's assumption 
As we see, this argument works only if we accept that perfect right triangles could possibly exist in the sensible world. The atomist can easily rebut this argument by insisting that all perfect mathematical objects are purely mental constructions that have no counterpart in the sensible world. There possibly exist some triangular objects in the sensible world that look approximately like perfect right triangles; but since their imperfectness appears only at the atomic level - that is perhaps undetectable by our sense organ - we cannot distinguish such triangular objects from perfect right triangles. Moreover, the Pythagorean Theorem is not precisely applicable to imperfect objects that look very similar to perfectly right triangles. In other words, the second premise of the above argument is false and there cannot exist in the sensible world any perfectly right triangle with the aforementioned descriptions to which the Pythagorean Theorem is precisely applicable. Accordingly, the above argument fails. Thus, if we construe Avicenna as holding a purely abstractionist-fictionalist view about mathematical objects, we cannot explain how Avicenna might have thought that his argument could reject atomism. The argument is sound only if literalism is true. This can be considered as another justification for why Avicenna should be interpreted as a literalist.

My literalist reading of Avicenna's philosophy of mathematics might be better understood in contrast with McGinnis's well-developed abstractionist alternative. He says:

[T] he estimative faculty is what allows the mathematician to consider perfect geometrical figures or numbers in the abstract even though these are never instantiated physically; it is the power that allows the physicists to imagine perfectly frictionless planes or a sphere touching a two-dimensional surface at a single point, even though again in the nitty-gritty world around us none of these exists. These mathematical abstracta, Avicenna says, exist by supposition (bi-l-fard), usually a supposition imagined by the estimative faculty. That is to say, while mathematical abstracta exist in a mental act of conceptualization (tasawwur), they do not exist, at least not in the exact way that the mathematician investigates them, in the concrete material particulars that populate the world. It is the estimative faculty, then, that provides mathematicians and (theoretical) physicists with an idealized picture of the world $^{65}$.

that atoms are cuboidal. If his analysis is valid, so is mine. But the other way around does not necessarily hold.

${ }^{65}$ McGinnis, "Experimental thoughts," p. 80; my emphasis. The textual ground of McGinnis's analysis is chapter I.2 of the "Introduction" of the "Healing" (Al-madhal, chap. I.2, 12-3) from which I have quoted TEXT 3 and TEXT 4 . As is clear from his analysis, we defend different readings of these passages. There is a parallel debate in the 
I agree with McGinnis that estimation plays a pivotal role in the mechanism of forming mathematical concepts. However, by contrast with him, I argued that perfect mathematical objects could possibly exist in the extramental world. Moreover, in the present context, the main role of estimation is perceiving what actually exists in the sensible world, rather than constructing a purely mental abstractum. Mathematical objects are, in the first place, perceived rather than produced, or so Avicenna seems to believe. The fact that by our estimation we separate mathematical objects from the specific matters they are attached to in the sensible world, does not imply that those objects do not exist in the sensible world ${ }^{66}$. This resembles the mechanism through which we perceive hostility. The fact that by our estimation we can separate hostility from the animal through seeing which we have perceived its hostility, does not imply that hostility does not exist in the sensible world. Mathematical objects are in this sense analogous to hostility and other attributes similar to it. They are all non-sensible connotational attributes that actually exist in the sensible world and can be perceived by estimation. They are not purely mental products ${ }^{67}$.

context of Aristotle's philosophy of mathematics. My reading of Avicenna is comparable to the literalist interpretations of Aristotle's ontology of mathematics as defended by, among others, Ian Mueller, "Aristotle on geometrical objects," Archiv für Geschichte der Philosophie, vol. 52, no. 2 (1970), p. 156-71, and "Aristotle's doctrine of abstraction in the commentators," in Richard Sorabji (ed.), Aristotle transformed: The ancient commentators and their influence (Ithaca, 1990), p. 463-80. By contrast, McGinnis's reading of Avicenna is analogous to the abstractionist-fictionalist interpretations of Aristotle as supported by, among others, Jonathan Lear, "Aristotle's philosophy of mathematics," Philosophical review, vol. 91, no. 2 (1982), p. 161-92, and Edward Hussey, "Aristotle on mathematical objects," Apeiron, vol. 24, no. 4 (1991), p. 105-33.

66 Avicenna sometimes says that mathematical objects are mujarrad. See, among others, Avicenna, The Physics of the Healing, chap. I.8, sec. $2 \& 6$. This fact can be considered as a justification of describing mathematical objects as mental abstracta. However, Avicenna's understanding of abstraction in this context is merely considering mathematical objects in separation (or isolation) from the specific species of matter they are accompanied with in the sensible world. In this sense, abstraction is not constructing a new entity. Rather, it is considering some specific features of some objects existing in the sensible world while overlooking their other features. In other words, abstraction in this context has primarily an epistemological - rather than ontological - function. Given this significant qualification, describing mathematical objects as abstracta is unproblematic.

67 The essence or quiddity ( $m \bar{a} h \bar{h} y a)$ of an imperfect geometrical shape existing in the sensible world differs from the essence of its perfect counterpart existing as an abstractum in the mind. For example, the essence of a perfectly right triangle to which the Pythagorean Theorem is applicable differs from the essence of an imperfect ob- 
Admittedly, there are still many other mathematical objects that are studied by mathematicians although they have no counterpart in the sensible world. Our conception of such objects will be formed, more than anything else, under the influence of imagination ${ }^{68}$. By combining different parts of objects previously perceived by estimation, imagination can mentally build some new mathematical objects ${ }^{69}$. But even these mental products, inasmuch as they are subject to mathematical studies, should be considered as attributes of material entities. In other words, they should be treated by mathematicians as if they are non-sensible properties of some actually existing sensible objects. These items grasped or produced respectively by estimation and imagination will be delivered to the intellect where the intervention of the Active intellect turns them into purely immaterial universal concepts.

\section{CONCLUSION}

According to Avicenna many mathematical objects actually exist in the sensible world. They are not however themselves sensible forms. They are specific connotational attributes of physical objects existing in the extramental world. We can perceive mathematical objects by the faculty of estimation. In this faculty, mathematical objects are still considered as properties of material things, but their association with the specific kinds of matter they are attached to in the sensible world is neglected. So mathematical objects are perceived as things associated with matter but not with a determinate species of it. There are of course many

ject to which the theorem is not precisely applicable. The former object has some essential properties that the latter lacks. So they do not share the same essence. Accordingly, we should provide an explanation of how we can grasp the quiddity of the objects that neither have a counterpart in the sensible world nor are composed of elements each of which has a counterpart in the sensible world. Avicenna's concept empiricism seems to suggest that there is no such explanation. This argument can be considered as a serious epistemological challenge against any purely abstractionist interpretation which does not compromise Avicenna's concept empiricism. Avicenna (The Metaphysics of the Healing, chap. VII.3, sec. 2-3) puts forward a very similar challenge to argue against mathematical Platonism. For a discussion of the subtleties of his argument see my "Avicenna against mathematical Platonism."

68 This act of imagination is the source of a potentiality for widening the domain of objects that can be studied by mathematicians. Ergo, Avicenna endorses some sort of literalism, on the one hand, and some sort of potentialism, on the other. See my "Avicenna on the nature of mathematical objects."

${ }^{69}$ In this respect there seems to be no disagreement between me and McGinnis. I cannot agree more with the description of the cognitive roles of imagination as it is presented in McGinnis's book. See McGinnis, Avicenna, p. 114-5. 
mathematical objects that we study in mathematics which have no counterpart in the extramental realm. According to Avicenna's epistemology, the faculty of imagination can construct such objects by analyzing, synthesizing, separating and combining different elements of the items previously perceived by and stored in the cognitive faculties. It is through the preparatory act of these two faculties that the intellect can grasp universal mathematical concepts. These faculties play necessary and ineliminable roles in perceiving mathematical concepts. I showed that, according to Avicenna's epistemology of mathematics, grasping mathematical concepts is strongly dependent on the data we receive from the sensible world. Someone who has no sense perception cannot obtain any mathematical concepts. This indicates that Avicenna endorses some sort of concept empiricism about mathematics.

My discussion of Avicenna's epistemology of mathematics was restricted to the conceptual level. Things change at the propositional level. It can be shown that according to Avicenna, after grasping the conceptual components of mathematical propositions, the intellect can assent to their truth without relying on any further perceptual experience. If so, after grasping the required mathematical concepts neither assenting to the truth of the principles of mathematics nor proving more complicated theorems based on these principles depends on the data we receive through our perceptual experiences. The intellect can, in principle, carry out both of these things without the assistance of other animal cognitive faculties. On my account, Avicenna's epistemology of mathematics is a mixture of concept empiricism and judgment rationalism. This paper was dedicated only to the former element. The latter must be studied in another work.

Acknowledgements. This paper is extracted from my $\mathrm{PhD}$ dissertation (on Avicenna's philosophy of mathematics) at the Faculty of Divinity of the University of Cambridge. I am thankful to my supervisor, Tony Street, and to the examiners of my viva, John Marenbon and Sajjad Rizvi for extremely helpful comments and discussions. Despite his disagreement with (at least part of) my view, Jon McGinnis generously spent time reading an earlier version of this paper and giving insightful feedbacks for which I am sincerely grateful to him. I should also thank Jari Kaukua for inviting me to present an earlier version of this paper in the Finnish Workshop in Medieval Philosophy (which took place in the Department of Social Sciences and Philosophy, University of Jyväskylä, Jyväskylä, Finland, November 30, 2018). I benefited a lot from the feedbacks I received from my audiences there. I owe Helia Tavakoli thanks for editing the French abstract. The final version of this paper was prepared while I was a Humboldt Postdoctoral Research Fellow at LMU Munich. I am thankful to the Alexander von Humboldt Foundation for their support. 